\title{
UV Stability of Poly(Lactic Acid) Nanocomposites
}

\author{
Andreia Araújo ${ }^{1}$, Gabriela Lema Botelho ${ }^{1}$, Manuela Silva ${ }^{1}$ and Ana Vera Machado ${ }^{2}$ \\ 1. Chemistry Department, University of Minho, Campus de Gualtar, Braga 4710-057, Portugal \\ 2. Institute for Polymers and Composites (IPC)/I3N, University of Minho, Campus de Azurém, Guimarães 4800-058, Portugal
}

Received: October 04, 2012 / Accepted: November 06, 2012 / Published: February 25, 2013.

\begin{abstract}
Poly(lactic acid) (PLA) is a biodegradable polyester with great interest because it is produced from renewable resources at low cost, is recyclable to its monomers and is a potential substitute to petroleum-based polymers. The ultraviolet (UV) degradation of polymers has huge importance since the resistance to ageing, especially to UV light, is a key factor for outdoor applications. Therefore, the goal of the present work was to study the effect of the addition of different organic modified montmorillonites (MMT) on the UV stability of PLA. Results showed a higher decrease of intrinsic viscosity, increase of crystallinity and chemical structure changes along degradation time for nanocomposites. Although the photodegradation mechanism is the same as the one previously proposed, the presence of organoclays in the PLA matrix enhances photodegradation.
\end{abstract}

Key words: Poly(lactic acid), UV stability, nanoclays.

\section{Nomenclature}

$\begin{array}{ll}\text { PLA: } & \text { Poly(lactic acid) } \\ \text { UV: } & \text { Ultraviolet } \\ \text { IR: } & \text { Infra-red } \\ \text { MMT: } & \text { Organic modified montmorillonite }\end{array}$

\section{Introduction}

In recent years, bio-based and biodegradable polymers have attracted special attention as substitutes for petroleum-based polymers $[1,2]$. Among biodegradable polyesters, Poly(lactic acid) (PLA) has great interest because it is produced from renewable resources at low cost, is non-toxic to environment, as well as, to the human body and can be recyclable to its monomers with a high yield [3]. In spite of having various good properties, PLA exhibits weaknesses in some aspects, such as, barrier and mechanical properties, thermal stability and heat distortion temperature, which are often not good enough for some demanding applications [2, 4, 5]. Therefore, research work has shown that these properties can be enhanced by the addition of low amounts of nanoclays [6-9].

Corresponding author: Gabriela Lema Botelho, Ph.D., professor, research fields: materials characterization, termal and photodegradation. E-mail: gbotelho@quimica.uminho.pt.
Nanoclays such as organic modified montmorillonite (MMT) are of particular interest due to their abundance, low cost and geometrical features [4]. Since nanocomposites are a new type of materials, it is important to have information about their effect on polymer stability during ageing under different conditions because the resistance to ageing, especially to UV light, is a key factor for outdoor applications [5, $10,11]$. In many cases, accelerated weathering is used to predict the lifetime of polymers under service conditions. Most accelerated weathering devices (Weather-Ometer, Xenontester, Suntester, etc.) show a lack of correlation between the stabilities measured with them and those that occur outdoor during natural exposure $[12,13]$. However, it was demonstrated that filtered xenon lamps have an spectrum, which is comparable to the UV spectrum of the sun and if operated at not too high temperatures, is expected to represent better outdoor ageing. Consequently, under these experimental conditions, the results obtained can be correlated with the results of natural exposure [14]. In previous works, it has been suggested that the photolysis mechanism of PLA proceeds via "Norrish type photo cleavage", specially Norrish II reaction, 
which was based on the increase of the absorption bands corresponding to hydroxyl and acrylic groups in infra-red (IR) spectra [3, 15, 16]. Janorkar, et al. [17] reported the occurrence of two degradation mechanisms of PLA under UV radiation. The first mechanism involves a photolysis reaction leading to breakage of the backbone $\mathrm{C}-\mathrm{O}$ bond. The second one involves photo-oxidation of PLA leading to the formation of hydroperoxide and its subsequent degradation to compounds containing carboxylic acid and diketone end groups. Furthermore, the photolysis of the diketone may lead to the homolytic cleavage of the C-O bond between the two carbonyl groups, resulting in two carbonyl radicals. This radical pair can undergo cage escape to form several photo-decomposed products [2, 17]. Recently, Gardette, et al. [10] proposed a mechanism based on the formation of an anhydride. This mechanism involves a classical hydrogen abstraction on the polymeric backbone at the tertiary carbon in the $\alpha$-position of the ester function leading to macroradicals formation. It is postulated that initiation of the photochemical reaction results from the presence of chromophoric defects in the polymer at very low concentrations. This mechanism contradicts the older mechanism reported in the literature, which is associated with a Norrish II-type photo-cleavage $[1,3,16]$.

While there are several research studies on UV degradation of PLA [1, 3, 5, 15, 16, 18, 19], only a few are published dealing with PLA nanocomposites $[2,5]$. Therefore, this study aims to investigate the effect of the addition of different MMT on the UV stability of PLA. Nanocomposites were prepared by melt mixing and the photodegradation of PLA and nanocomposites was performed in a Xenotest. The samples collected along the time were characterized by Fourier transform infrared spectroscopy (FTIR) and 1hydrogen-nuclear magnetic resonance ( $\left.{ }^{1} \mathrm{H}-\mathrm{NMR}\right)$ spectroscopy, differential scanning calorimetry (DSC) and intrinsic viscosity measurements.

\section{Experiments}

\subsection{Materials}

A commercial grade PLA (3251D) was supplied by NatureWorks LLC (USA). The three nanoclays (modified MTT) used were supplied by Southern Clay Products (USA), Cloisite 30B (C30B) and Cloisite 15A (C15A), and by Laviosa Mineraria (Italy), Dellite 43B (D43B). Chloroform and deuterated chloroform were purchased from Lab-Scan and Acros Organics, respectively, and used as received.

\subsection{Sample Preparation}

Nanocomposites were prepared by melt mixing following the next steps. PLA pellets and nanoclays were dried in a vacuum oven at $60{ }^{\circ} \mathrm{C}$ for $12 \mathrm{~h}$. PLA with 3 wt. $\%$ of C15A, C30B and D43B were pre-mixed and introduced in a Haake batch mixer (HAAKE Rheomix $600 \mathrm{OS}$; volume $69 \mathrm{~mL}$ ) equipped with two rotors running in a counter-rotating way. The rotor speed was $80 \mathrm{rpm}$ and the set temperature was $190^{\circ} \mathrm{C}$. After $5 \mathrm{~min}$ of mixing time, the total sample was removed.

The prepared nanocomposites were pressed into thin films by compression moulding under $200^{\circ} \mathrm{C}$ and 30 ton for $60 \mathrm{~s}$. The thickness of each film (ca. $40 \mu \mathrm{m}$ ) was measured with a pachymeter Mitutoyo.

\subsection{Photodegradation}

The accelerated weathering of PLA and PLA nanocomposites were carried out in a XenoTest $150 \mathrm{~S}$ chamber from Heraeus (Original Hanau) equipped with a filtered Xenon lamp with an intensity of $60 \mathrm{Wm}^{-2}$ according to standard procedures [20]. The light of the xenon lamp was filtered under $300 \mathrm{~nm}$ with an UV window combined with six IR filter glasses. The XenoTest creates an accelerated environment of the natural weathering conditions, simulating materials conditions during its lifetime, i.e., daylight exposure to heat, oxygen and humidity. The accelerated weathering conditions are listed in Table 1. 
Table 1 Conditions in accelerated weathering chamber.

\begin{tabular}{lccl}
\hline $\begin{array}{l}\text { Cycle } \\
\text { period }\end{array}$ & $\begin{array}{c}\text { Cycle } \\
(\mathrm{min})\end{array}$ & $\begin{array}{c}\text { time Temperature } \\
\left({ }^{\circ} \mathrm{C}\right)\end{array}$ & $\begin{array}{l}\text { Relative } \\
\text { humidity }(\%)\end{array}$ \\
\hline Rain & 18 & 23.0 & 85.0 \\
Dry & 102 & 30.0 & 58.0 \\
\hline
\end{tabular}

PLA and PLA nanocomposites with dimensions of $135 \times 45 \mathrm{~mm}$ were cut from the thin films. Samples were removed after 100, 200, 300, 400, 500 and $600 \mathrm{~h}$ of exposure.

\subsection{Characterization}

\subsubsection{X-ray Diffraction (XRD)}

The diffraction patterns were obtained using a diffractometer (AXS Nanostar-D8 Discover, Bruker) equipped with a $\mathrm{CuK} \alpha$ generator $(\lambda=1.5404 \AA)$ at 40 $\mathrm{kV}$ and $40 \mathrm{~mA}$, in a $2 \theta$ range from $0.08-10^{\circ}$. The nanoclays were analyzed directly, whereas the nanocomposite samples were previously compression moulded into disks with a diameter of $20 \mathrm{~mm}$ and a thickness of $4 \mathrm{~mm}$.

2.4.2 ${ }^{1} \mathrm{H}$ Nuclear Magnetic Resonance Spectroscopy ( ${ }^{1} \mathrm{H}$ NMR)

${ }^{1} \mathrm{H}$ NMR spectra of initial PLA samples and after 300 and $600 \mathrm{~h}$ of degradation were recorded on a Varian Unity Plus $300 \mathrm{MHz}$ spectrometer using deuterated chloroform as solvent and tetramethylsilane as internal standard.

\subsubsection{Intrinsic Viscosity}

The intrinsic viscosity $(\eta)$ of initial and 200, 400 and $600 \mathrm{~h}$ degraded samples was determined using an Ubbelohde capillary viscometer with $5 \mathrm{mg} \cdot \mathrm{ml}^{-1}$ solutions in chloroform at $25.0 \pm 0.5^{\circ} \mathrm{C}$ and according to the following equation [21]:

$$
\eta=\frac{\sqrt{2\left(\left(\eta_{\mathrm{r}}-1\right)-\ln \eta_{\mathrm{r}}\right)}}{\mathrm{c}}
$$

where $\eta_{\mathrm{r}}$ is the relative viscosity and $c$ is the polymer solution concentration.

For each sample five measurements were performed to determinate the solution viscosity.

2.4.4 Fourier Transform Infrared Spectroscopy (FTIR)

Room temperature infrared spectra of the initial and degraded films were recorded on an ABB FTLA 2000 spectrometer in the range $4,000-500 \mathrm{~cm}^{-1}$ by averaging 16 scans and using a resolution of $4 \mathrm{~cm}^{-1}$.

\subsubsection{Differential Scanning Calorimetry (DSC)}

Thermal properties were determined in a Mettler Toledo (2000) DSC $821^{\mathrm{e}}$ under nitrogen. Approximately $6 \mathrm{mg}$ of each sample were cut from the films and placed in an aluminium pan. The analysis was performed in three steps: first heating from 30 to $250{ }^{\circ} \mathrm{C}$ at $50{ }^{\circ} \mathrm{C} / \mathrm{min}$, cooling from 250 to $30^{\circ} \mathrm{C}$ at 10 ${ }^{\circ} \mathrm{C} / \mathrm{min}$, and second heating from 30 to $250{ }^{\circ} \mathrm{C}$ at 10 ${ }^{\circ} \mathrm{C} / \mathrm{min}$. Two minute isothermal plateau were performed between the ramps. The cold crystallization enthalpy $\left(\Delta H_{c c}\right)$, and melting enthalpy $\left(\Delta H_{m}\right)$ were determined from second heating curves. The crystallinity degree $\left(\chi_{c}\right)$ was obtained using the following equation [22]:

$$
\chi_{\mathrm{c}}(\%)=\left(\frac{\Delta \mathrm{H}_{\mathrm{m}}-\Delta \mathrm{H}_{\mathrm{cc}}}{\Delta \mathrm{H}_{\mathrm{m}}^{0} \times(1-\text { clay })}\right) \times 100
$$

where $\Delta H_{m}$ and $\Delta H_{c c}$ are, respectively, the experimental melting enthalpy and the cold crystallization enthalpy obtained for the samples, $\Delta H_{m}^{0}$ is the melting enthalpy of the $100 \%$ PLA (93.0 J/g [22]) and wt.\% clay is the weight percentage of the incorporated nanoclay.

\section{Results and Discussion}

\subsection{X-Ray Diffraction}

Fig. 1 shows, as an example, the XRD patterns of

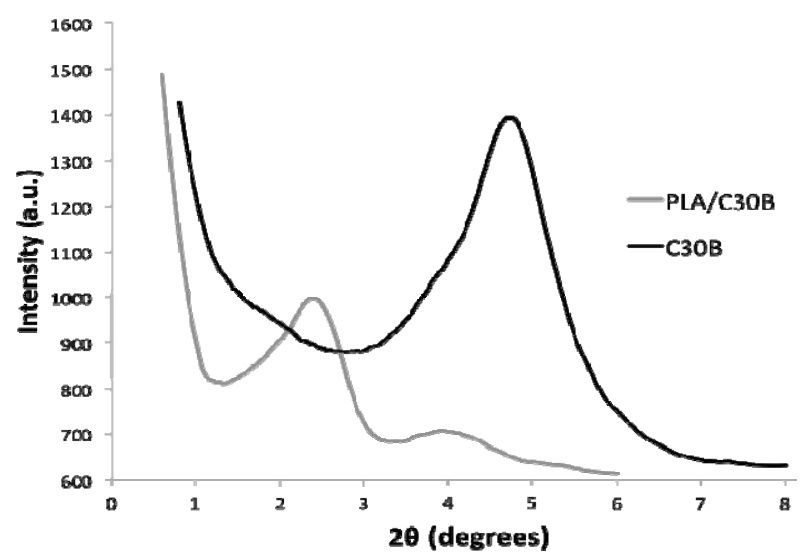

Fig. 1 X-ray diffractogram recorded for $\mathrm{C30B}$ and respective nanocomposite. 
the nanoclay $\mathrm{C} 30 \mathrm{~B}$ and correspondent nanocomposite prepared with $3 \mathrm{wt} . \%$. The change in diffraction angle allows to evaluate the dispersion of mineral sheets within the polymer matrix [2, 23]. Comparing diffraction peak (001) plane of powder nanoclays and nanocomposites, a shift to lower angles was observed for all prepared nanocomposites. The decrease of the diffraction angles means that PLA macromolecules were inserted between the nanoclay layers and nanocomposites with an intercalated structure were obtained. The d-spacing values (basal distance between clay layers) were calculated using Bragg's law $(\lambda=$ $2 d \sin \theta ; d$ is the interlayer $\mathrm{d}$-spacing and $\lambda$ is the wavelength). The calculated $d_{001}$ distance expands 1.60 $\mathrm{nm}$ for PLA/C30B, $0.62 \mathrm{~nm}$ for PLA/C15A and 1.65 $\mathrm{nm}$ for PLA/D43B. According to these results, the nanocomposites prepared with $\mathrm{C} 30 \mathrm{~B}$ and $\mathrm{D} 43 \mathrm{~B}$ exhibited higher interlayer space than with $\mathrm{C} 15 \mathrm{~A}$.

SEM results obtained in a previous work [24] showed homogeneous nanoclay dispersion in all samples, excepted in PLA/C15A nanocomposites, where agglomerates were observed.

\section{$3.2{ }^{1} \mathrm{H} N M R$ Analysis}

Analyses by ${ }^{1} \mathrm{H}$ NMR were performed on the initial and degraded samples to evaluate if changes in the chemical structure of PLA occurred during photodegradation. The chemical shift $(\delta)$ values obtained in the ${ }^{1} \mathrm{H}$ NMR spectra and the corresponding groups are listed in Table 2. It can be noticed that the assignments obtained are in well agreement with Ref. [25]. No changes in chemical shift values were observed between PLA $0 \mathrm{~h}$, PLA $300 \mathrm{~h}$ and PLA $600 \mathrm{~h}$. However, there are differences in the signal intensities and in proton area ratio $\left(\mathrm{CH}_{3} / \mathrm{CH}\right)$, which decrease with degradation. This ratio has a theoretical value of 3 and it must remain constant if degradation takes place upon ester linkage degradation, hydrolysis or radical degradation, among others [26]. According to Ref. [26] only pyrolytic elimination (which is responsible for the transformation of $\mathrm{CH}-\mathrm{CH}_{3}$ into $\mathrm{CH}=\mathrm{CH}_{2}$ ) can be
Table $2{ }^{1}$ H NMR data of PLA samples.

\begin{tabular}{llll}
\hline & $\delta \mathrm{CH}_{3}(\mathrm{ppm})$ & $\delta \mathrm{CH}(\mathrm{ppm})$ & Relative area $\mathrm{CH}_{3} / \mathrm{CH}$ \\
\hline PLA 0 h & $1.56-1.60$ & $5.14-5.21$ & 3.71 \\
PLA 300 h & $1.58-1.60$ & $5.14-5.21$ & 3.26 \\
PLA 600 h & $1.58-1.60$ & $5.13-5.20$ & 3.18 \\
\hline
\end{tabular}

responsible for a lower ratio. Since, there was no signal for $\mathrm{CH}_{2}$ protons in ${ }^{1} \mathrm{H} \mathrm{NMR}$, this mechanism, if present, must be secondary and of minor importance during the photodegradation pathway.

\subsection{Intrinsic Viscosity Changes}

Intrinsic viscosity $(\eta)$ measurements were also performed in initial and degraded samples along time and the results are presented in Fig. 2. Before degradation all nanocomposites exhibited a lower $\eta$ than PLA. This decrease might be related with chain scission that occurred during its preparation, due to high temperature, shear during melt mixing and reactions between PLA and reactive groups of the clay modifiers [2]. A very high sensitivity of PLA to thermal degradation during melt processing has been reported, even in the presence of antioxidant [27]. It is also published that hydrolysis of PLA matrix is accelerated by high temperature, shear and the reactive groups of the modifiers of each nanoclay [2, 21].

PLA viscosity decreases slightly after $200 \mathrm{~h}$ of photodegradation and then this value remain practically unchanged until $600 \mathrm{~h}$. Contrarily, nanocomposites viscosity gradually decreases with increasing degradation time and the major decrease was observed for samples prepared with $\mathrm{C} 30 \mathrm{~B}$ and

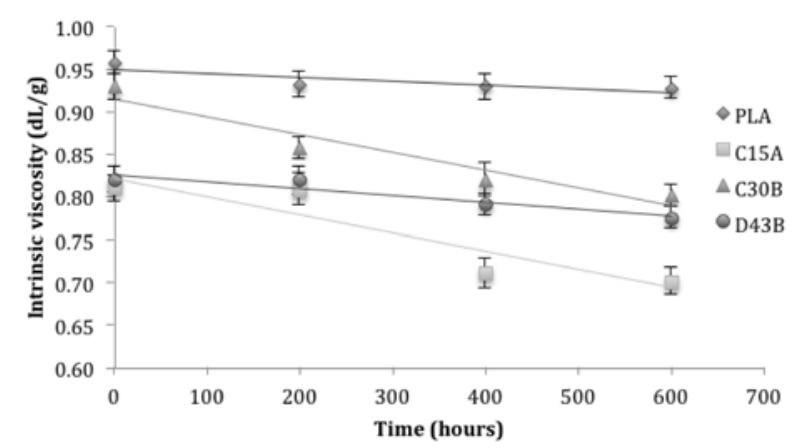

Fig. 2 Intrinsic viscosity of initial and along degradation for PLA and PLA with nanoclays. 
C15A. The reduction of PLA and PLA nanocomposites viscosity indicates that chain scission plays an important role in the degradation mechanism. This result is in agreement with the literature, where it is reported that photodegradation of PLA causes chain cleavage and formation of lower molecular weight compounds $[1,18]$.

As can be seen in Fig. 2, the absolute slope of the lines adjusted to the experimental values, which is an indicator of photodegradation rate, is higher for nanocomposites with $\mathrm{C} 30 \mathrm{~B}$ and $\mathrm{C} 15 \mathrm{~A}$. A possible explanation for higher chain scission in the sample containing $\mathrm{C} 30 \mathrm{~B}$ is the presence of hydroxyl groups and slightly higher content of metal ions in this nanoclay, which are known to accelerate the photodegradation. The decrease in molecular weight of the nanocomposite containing $\mathrm{C} 15 \mathrm{~A}$ was not expected since this nanoclay does not present reactive functional groups. Therefore, this can be probably associated to a higher amount of more unstable quaternary ammonium surfactant.

\subsection{Chemical Structure Analysis}

FTIR spectra of PLA and PLA nanocomposites with $\mathrm{C} 30 \mathrm{~B}$ were obtained before and after 300 and $600 \mathrm{~h}$ of photodegradation. The infrared spectra of PLA present (Fig. 3) the characteristic bands of the polymer [2, 8, 25, 28-30] identified in a previous work [24]. No significant changes can be detected after degradation; no vibration modes are suppressed or appear due to degradation. Only a slight increase of the intensity of some bands was perceived. This is in line with viscosity measurements, as photodegraded PLA did not show significant decrease in intrinsic viscosity.

Fig. 4 shows the infrared spectra obtained for nanocomposite PLA/C30B before and after photodegradation. Even though the overall response of the FTIR spectra of non-degraded sample is quite similar to the one obtained for PLA (Fig. 3), the intensity of the bands increases after degradation. An enlargement of the band corresponding to $\mathrm{C}=\mathrm{O}$ and the appearance and increase of a shoulder at $1,845 \mathrm{~cm}^{-1}$ can be noticed along degradation time.

The photodegradation of PLA was previously described in literature to occur according to a Norrish II mechanism of carbonyl polyester $[1,3,16]$. This mechanism involves chain cleavage and the formation of $\mathrm{C}=\mathrm{C}$ bonds and hydroperoxides $\mathrm{O}-\mathrm{H}$ at newly formed chain terminals. However, this mechanism was proposed based on results obtained with a light source emitting in the UV domain from $220 \mathrm{~nm}$ [16], thus, in a region where the carbonyl groups of aliphatic polyester

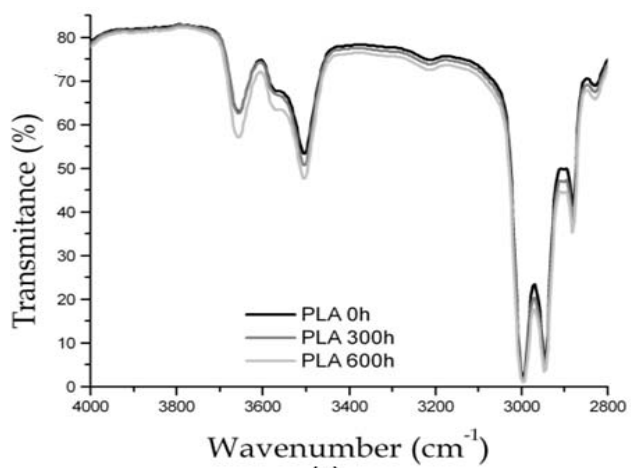

(a)

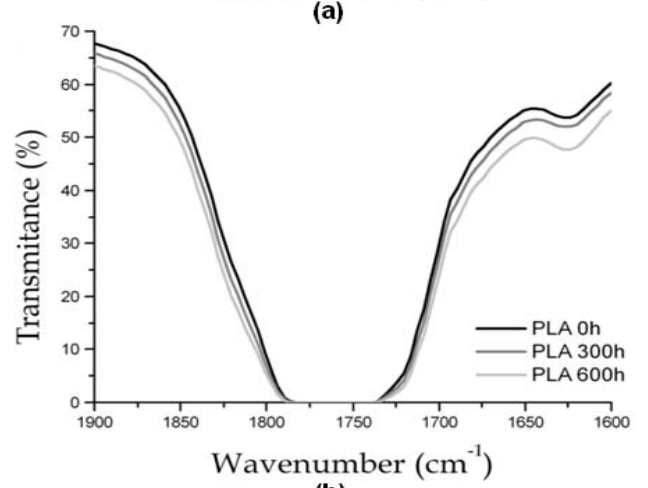

(b)

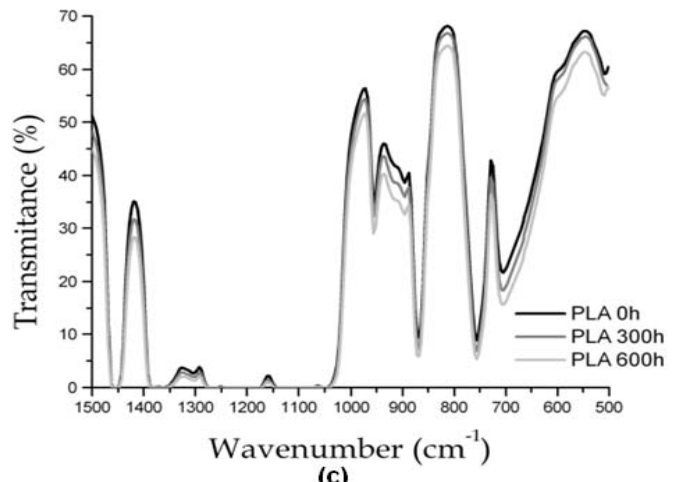

(c)

Fig. 3 FTIR spectra of PLA obtained before and after 300 and $600 \mathrm{~h}$ of photodegradation in three different region: (a) $4,000-2,800 \mathrm{~cm}^{-1}$; (b) 1,900-1,600 $\mathrm{cm}^{-1}$ and (c) $1,500-500 \mathrm{~cm}^{-1}$. 


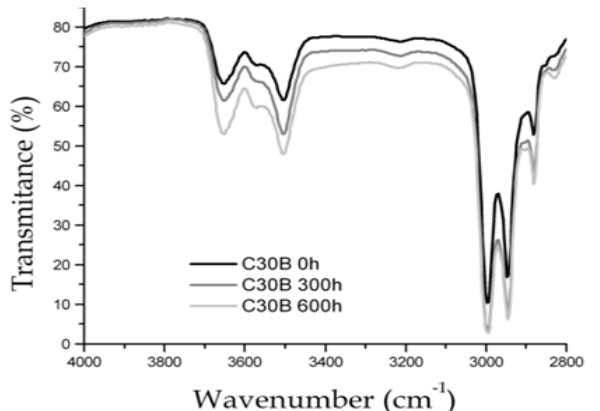

(a)

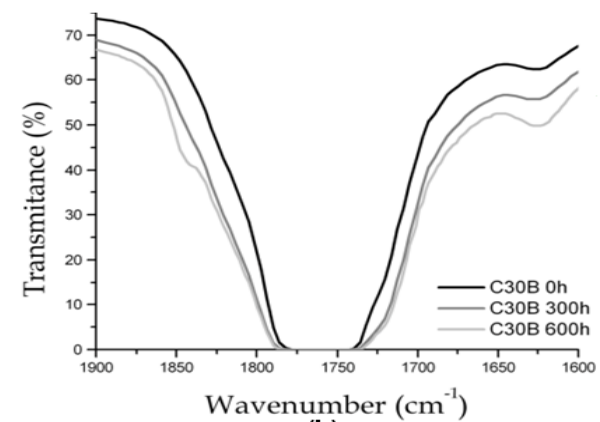

(b)

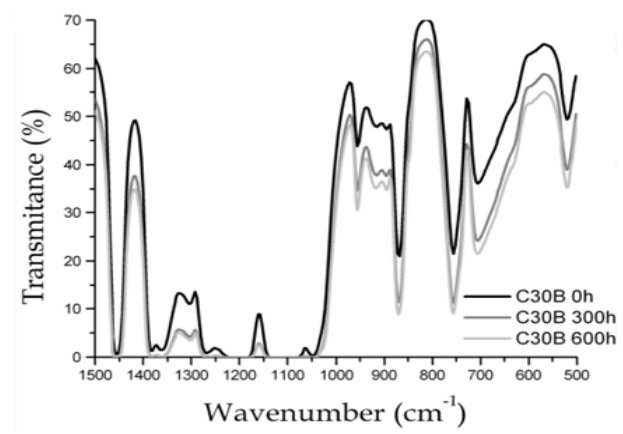

(c)

Fig. 4 FTIR spectra of PLA with 3 wt.\% C30B obtained before and after 300 and $600 \mathrm{~h}$ of photodegradation in three different region: (a) 4,000-2,800 $\mathrm{cm}^{-1}$, (b) $1,900-1,600 \mathrm{~cm}^{-1}$ and (c) $1,500-500 \mathrm{~cm}^{-1}$.

can absorb energy and consequently lead to photoreaction $[5,10]$. These conditions do not simulate natural outdoor exposure, thus in this work the UV light wavelengths bellow $300 \mathrm{~nm}$ were filtered.

Based on the formation of an anhydride, new mechanisms have been proposed [10, 17] and Fig. 5 presents PLA photodegradation mechanism proposed by Bocchini, et al. [5]. Usually begins by radical formed from impurities by UV light or thermal decomposition. The reaction with higher probability is the abstraction of tertiary hydrogen from PLA chain with the formation of a tertiary radical P• (1) (Fig. 5).
This radical can react with oxygen to form a peroxide radical (2) (Fig. 5), which may easily abstract another hydrogen from a tertiary carbon with the formation of an hydroperoxide and the initial radical P• (3) (Fig. 5). Then, the hydroperoxide undergoes photolysis (4) (Fig. 5) with the formation of the $\mathrm{HO} \bullet$ and a $\mathrm{PO} \bullet$ radical that can further evolve by $\beta$-scission (5) (Fig. 5). Taking into account the stability of the different fragments, the most probable $\beta$-scission appears to be the (5b) (Fig. 5) reaction, leading to the formation of anhydride groups.

Based on the literature data, the band that appeared at $1,845 \mathrm{~cm}^{-1}$ is assigned to anhydride functions [5, 10], which is in concordance with pathway (5b) (Fig. 5) in the photodegradation mechanism proposed by Bocchini, et al. [5] and presented in Fig. 5.

Results obtained with incorporation of C15A and D43B were similar to the one with C30B (results not shown).

According to Refs. [8, 25, 29, 31], there are bands related to amorphous phase of PLA (955 and 869 $\left.\mathrm{cm}^{-1}\right)$ and to crystalline phase $\left(755,912\right.$ and $\left.923 \mathrm{~cm}^{-1}\right)$. As all these bands are present in FTIR spectra of the PLA and PLA nanocomposites and all of them increase with degradation time, the results were not elucidative in what concerns to the effect of photodegradation on crystallinity. In order to overcome this problem, DSC measuments were performed.

\subsection{Thermal Analysis}

Thermal properties of PLA and PLA nanocomposites were evaluated by DSC. The crystallinity degree $(\chi)$ of PLA and PLA nanocomposites before and after $600 \mathrm{~h}$ of photodegradation is depicted in Fig. 6. It is known that the addition of the nanoclays promotes the extent of crystallization of PLA, indicating that they can act as nucleating agents $[9,22]$. Even though this was observed for the nanocomposites prepared with $\mathrm{C} 30 \mathrm{~B}$ and $\mathrm{D} 43 \mathrm{~B}$, it was not for the one with $\mathrm{C} 15 \mathrm{~A}$, in this case the crystallinity was lower than for PLA. This can 

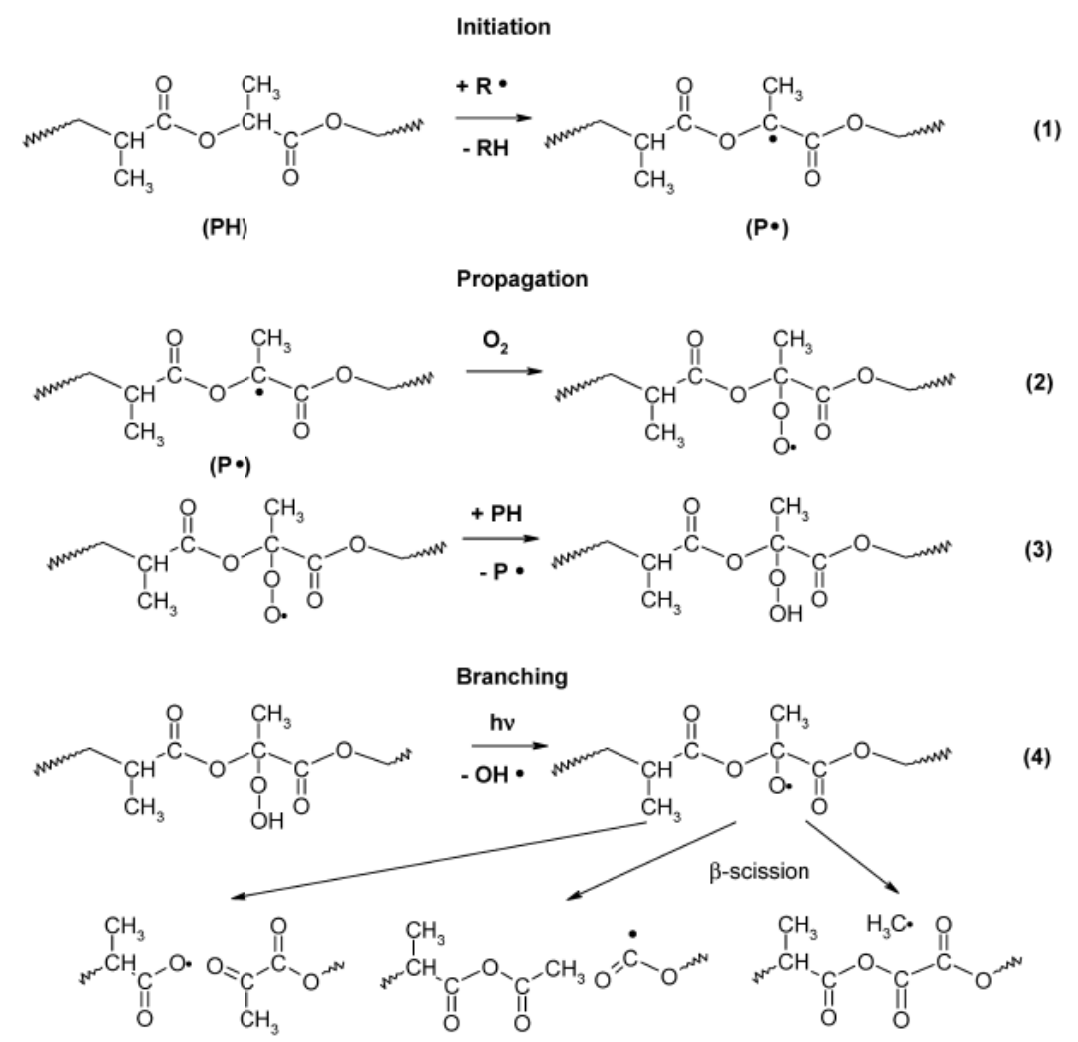

(5a)

(5b)

(5c)

Fig. 5 PLA photodegradation mechanism proposed by Bocchini, et al. [5].

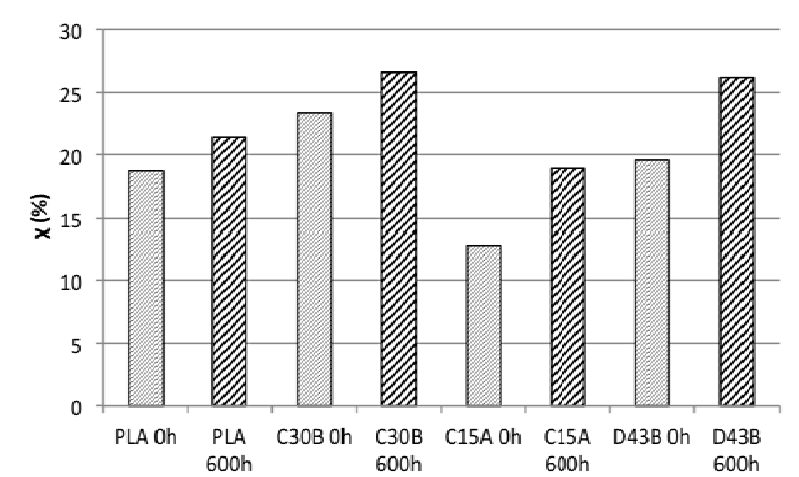

Fig. 5 Crystallinity degree $(\chi)$ of initial and $600 \mathrm{~h}$ degraded PLA and PLA nanocomposites.

probably be associated with the nanoclay agglomarates.

After degradation an increase of crystallinity degree was noticed for all samples, but was higher for nanocomposites. Since the increase is crystallinity which is

associated with the higher mobility of the small molecules that result from chain scission, would be expected. Viscosity and infrared results also showed that higher differences were found for nanocomposites.

\section{Conclusions}

The effect of different organically modified MMT (Cloisite 30B, Cloisite 15A and Dellite 43B) on the photodegradation of PLA was investigated. Results from ${ }^{1} \mathrm{H}-\mathrm{NMR}$ and intrinsic viscosity show that chain scission occurs along degradation time. The reduction of viscosity of PLA and PLA nanocomposites indicates that chain scission plays an important role among the degradation mechanisms and photodegradation rates were higher for nanocomposites containing $\mathrm{C} 30 \mathrm{~B}$ and C15A. While FTIR spectra of PLA did not present significant changes along degradation, for nanocomposites the appearance and increase of a shoulder, at $1,845 \mathrm{~cm}^{-1}$, along degradation time indicate that the presence of nanoclays enhance 
photodegradation according to a mechanism previously proposed. DSC results evidence the nucleation effect of the nanoclays and that the formation of lower molecular weight compounds during photodegradation caused an increase of the crystallinity degree of the samples.

\section{References}

[1] S. Belbachir, F. Zaïri, G. Ayoub, U. Maschke, M. Naït-Abdelaziz, J.M. Gloaguen, et al. Modelling of photodegradation effect on elastic-viscoplastic behaviour of amorphous polylactic acid films, Journal of the Mechanics and Physics of Solids 58 (2010) 241-255.

[2] L. Zaidi, M. Kaci, S. Bruzaud, A. Bourmaud, Y. Grohens, Effect of natural weather on the structure and properties of polylactide/Cloisite 30B nanocomposites, Polymer Degradation and Stability 95 (2010) 1751-1758.

[3] H. Tsuji, Y. Echizen, Y. Nishimura, Enzymatic degradation of poly (1-lactic acid): Effects of UV Irradiation, Journal of Polymers and the Environment 14 (2006) 239-248.

[4] S. Dadbin, F. Naimian, A. Akhavan, Poly (lactic acid)/layered silicate nanocomposite films: Morphology, mechanical properties, and effects of $\gamma$-radiation, Journal of Applied Polymer Science 122 (2011) 142-149.

[5] S. Bocchini, K. Fukushima, A.D. Blasio, A. Fina, A. Frache, F. Geobaldo, Polylactic acid and polylactic acid-based nanocomposite photooxidation, Biomacromolecules 11 (2010) 2919-1926.

[6] H. Zhu, Q. Zhu, J. Li, K. Tao, L. Xue, Q. Yan, Synergistic effect between expandable graphite and ammonium polyphosphate on flame retarded polylactide, Polymer Degradation and Stability 96 (2011) 183-189.

[7] T.M. Wu, C.Y. Wu, Biodegradable poly(lactic acid)/chitosan-modified montmorillonite nanocomposites: Preparation and characterization, Polymer Degradation and Stability 91 (2006) 2198-2204.

[8] X. Wu, J. Yuan, Y. Yu, Y. Wang, Preparation and characterization of polylactide/montmorillonite nanocomposites, Journal of Wuhan University of Technology-Materials Science Edition 24 (2009) 562-565.

[9] D. Lewitus, S. McCarthy, A. Ophir, S. Kenig, The effect of nanoclays on the properties of PLLA-modified polymers part 1: Mechanical and thermal properties, Journal of Polymers and the Environment 14 (2006) 171-177.

[10] M. Gardette, S. Thérias, J.L. Gardette, M. Murariu, P. Dubois, Photooxidation of polylactide/calcium sulphate composites, Polymer Degradation and Stability 96
(2011) 616-623.

[11] M.S. Islam, K.L. Pickering, N.J. Foreman, Influence of accelerated ageing on the physico-mechanical properties of alkali-treated industrial hemp fibre reinforced poly(lactic acid) (PLA) composites, Polymer Degradation and Stability 95 (2010) 59-65.

[12] F.M. Duarte, G. Botelho, A.V. Machado, Photo-degradability of ketone modified PS/HIPS blends, Polymer Testing 25 (2006) 91-97.

[13] A. Copinet, C. Bertrand, A. Longieras, V. Coma, Y. Couturier, Photodegradation and biodegradation study of a starch and poly (lactic acid) coextruded material. Journal of Polymers and the Environment 11 (2003) 169-179.

[14] G. Botelho, M.M. Silva, A.M. Gonçalves, V. Sencadas, J. Serrado-Nunes, S. Lanceros-Mendez, Performance of electroactive poly(vinylidene fluoride) against UV radiation, Polymer Testing 27 (2008) 818-822.

[15] N. Yasuda, Y. Wang, T. Tsukegi, Y. Shirai, H. Nishida, Quantitative evaluation of photodegradation and racemization of poly(l-lactic acid) under UV-C irradiation, Polymer Degradation and Stability 95 (2010) 1238-1243.

[16] E. Ikada, Photo-and bio-degradable polyesters, Photodegradation behaviors of aliphatic polyesters, Journal of Photopolymer Science and Technology 10 (1997) 265-270.

[17] A.V. Janorkar, A.T. Metters, D.E. Hirt, Degradation of poly (L-lactide) films under ultraviolet-induced photografting and sterilization conditions, Journal of Applied Polymer Science 106 (2007) 1042-1047.

[18] H. Tsuji, H. Sugiyama, Y. Sato, Photodegradation of poly (lactic acid) stereocomplex by UV-irradiation, Journal of Polymers and the Environment (2012) 1-7.

[19] H. Tsuji, Y. Echizen, Y. Nishimura, Photodegradation of biodegradable polyesters: A comprehensive study on poly (1-lactide) and poly ( -caprolactone), Polymer Degradation and Stability 91 (2006) 1128-1137.

[20] ISO-4892-2, Plastics-Methods of Exposure to Laboratory Light Sources: Part 2. Xenon-Arc Lamps, 2006.

[21] Q. Zhou, M. Xanthos, Nanosize and microsize clay effects on the kinetics of the thermal degradation of polylactides, Polymer Degradation and Stability 94 (2009) 327-338.

[22] K. Fukushima, D. Tabuani, M. Dottori, I. Armentano, J.M. Kenny, G. Camino, Effect of temperature and nanoparticle type on hydrolytic degradation of poly(lactic acid) nanocomposites, Polymer Degradation and Stability 96 (2011) 2120-2129.

[23] S.S. Ray, M. Okamoto, Polymer/layered silicate nanocomposites: A review from preparation to processing, Progress in Polymer Science 28 (2003) 1539-1641. 
[24] A.G.B. Araújo, A.V. Machado, Thermal stability of Poly(lactic acid) nanocomposites, Submited to Applied Clay Science, 2012.

[25] X. Liu, Y. Zou, W. Li, G. Cao, W. Chen, Kinetics of thermo-oxidative and thermal degradation of poly(d,l-lactide) (PDLLA) at processing temperature, Polymer Degradation and Stability 91 (2006) 3259-3265.

[26] F. Carrasco, P. Pagès, J. Gámez-Pérez, O.O. Santana, M.L. Maspoch, Processing of poly(lactic acid): Characterization of chemical structure, thermal stability and mechanical properties, Polymer Degradation and Stability 95 (2010) 116-125.

[27] J.K. Pandey, R.K. Raghunatha, K.A. Pratheep, R.P. Singh, An overview on the degradability of polymer nanocomposites, Polymer Degradation and Stability 88 (2005) 234-250.
[28] J. Matusik, E. Stodolak, K. Bahranowski, Synthesis of polylactide/clay composites using structurally different kaolinites and kaolinite nanotubes, Applied Clay Science 51 (2011) 102-109.

[29] E. Meaurio, N. Lopez-Rodriguez, J. Sarasua, Infrared spectrum of poly (L-lactide): Application to crystallinity studies, Macromolecules 39 (2006) 9291-9301.

[30] G. Kister, G. Cassanas, M. Vert, Effects of morphology, conformation and configuration on the IR and Raman spectra of various poly (lactic acid)s, Polymer 39 (1998) 267-273.

[31] S. Sato, M. Ono, J. Yamauchi, S. Kanehashi, H. Ito, S. Matsumoto, et al., Effects of irradiation with vacuum ultraviolet xenon excimer lamp at $172 \mathrm{~nm}$ on water vapor transport through poly(lactic acid) membranes, Desalination 287 (2012) 290-300. 